\title{
Research of Grain Emergency Logistics System
}

\author{
Xiao Qing Bi \& Dong Zhang \\ School of Tianjin University of Technology, Tianjin 300384, China
}

\begin{abstract}
This article on food emergency logistics system were reviewed, mainly summarizes the research progress in emergency logistics, large-scale natural disasters and public crises both have serious social impact and huge economic losses, emergency logistics system has an effective prevention and harm reduction function. In recent years, it is the continuous occurrence of a series of major natural disasters. The majority of the people about natural disasters cause enormous damage about property, the social economic development had brought unexpected hazards. Disaster rescue work requires a lot of human and financial resources to be protected, how to do emergency dispatching scientific and effective organization of disaster supplies is particularly projections. And the food is heavy millions of supplies in many relief supplies, after the disaster organize relevant personnel to conduct a special study about food emergency logistics system, it is the most important thing that is designed to meet the emergency situation on the ground grain logistics system.
\end{abstract}

KEYWORD: Emergency Logistics System; Economic development; Emergency dispatching

\section{INTRODUCTION}

Emergency Logistics refers to the response to major natural disasters, sudden public health incidents, public safety and military conflict and other emergencies and human, financial and material needs of a special emergency supply logistics and distribution activities, it seeks to the goal is to maximize the benefits of time and minimize disaster losses. to establish a scientific and orderly mechanisms for emergency logistics is one of the measures to deal with emergencies of our indispensable, it is also for the community to provide protection guardian. It is particularly important national security component, and reflects the level of development of a country's comprehensive national strength. It also relates to the country's peaceful relations with the social harmony and stability, and the people's interests are inseparable (B.Ombuki.2006). It also provides material basis and technical support for the effective implementation of emergency management and rescue work closely with the field.

\section{THE DESCRIPTION OF PROBLEMS AND SOLUTIONS}

To ensure that in the face of severe natural disasters and a state of emergency when the "eat well buy" the bottom line of the food supply goals are achieved in the shortest time to build a scientific and safe food security emergency supply outlets, for a short time, the completion of scientific layout, facilities, operate efficiently, and guarantee complete emergency food supply security system. Emergency food logistics facilities (node) should be closely around the "Emergency" function to build, each node in logistics facilities must also bear the ordinary logistics tasks with emergency function, so the cost is relatively expensive.

Taking into account the food emergency logistics node only when the outbreak of large-scale emergencies to fully perform its functions, in order to save costs and reduce the financial burden on local governments.

Therefore need to study how to carry out scientific and reasonable emergency logistics facility layout nodes, these nodes logistics facilities as little as possible in the total number of logistics facilities and each node can cover more area needs as much as possible, depending on the paper tries emergency distribution point region emergency logistics center constructed around the emergency facility layout model (Denis R. Towill. 1997). 
Table 1 Summary of Shijiazhuang City the emergency logistics nodes

\begin{tabular}{|l|l|}
\hline \multirow{2}{*}{$\begin{array}{l}\text { Population } \\
\text { Enclave }\end{array}$} & $\begin{array}{l}\text { 1. The west area, 2. Yu hua District, } \\
\text { 3. Xinhua District, 4. Luan cheng, } \\
\text { Town 8. Promise Counties, } \\
\text { 9. Jinju city, 10. Xin ji Downtown }\end{array}$ \\
\hline $\begin{array}{l}\text { food } \\
\text { Repository }\end{array}$ & $\begin{array}{l}\text { Shijiazhuang the provincial grain reserve, } \\
\text { Gaocheng State Grain Reserve }\end{array}$ \\
\hline $\begin{array}{l}\text { Distribution } \\
\text { stations }\end{array}$ & $\begin{array}{l}\text { Nan qiao, Bei wa Township, Kong South } \\
\text { town, Qing he Township, Su yang Town- } \\
\text { ship, Wang Xi Zhang Township, Zhou } \\
\text { Township, New Town, show Town, Hao } \\
\text { Township, East County homes back }\end{array}$ \\
\hline Victims in settlements do not specify in ad- \\
Settlements
\end{tabular}

Model: The location set covering mathematical model can solve the problems described above spatial layout constraint emergency logistics facilities nodes, the model was first proposed by the Toregas, Which requires emergency logistics facilities in all nodes to meet the emergency needs of further research can meet the needs and the number of emergency logistics in the aggregate a minimum of logistics facilities nodes, these nodes emergency logistics facilities to cover the food needs to point to all the affected areas. Location set covering model can try to relax the specifications defined in the computer by running a general linear programming procedures to obtain the answer, in most cases, the model can be obtained by conventional integer solution of the problem and in this paper is used the minimum number a heuristic algorithm to solve the node coverage.

\section{SPECIFIC EXAMPLES OF CALCULATION}

In order to improve a specific area of major emergencies food emergency response capacity, we need to plan the construction of a number of food emergency logistics center, now in Shijiazhuang, Hebei Province, Shijiazhuang research throughout the region how food emergency logistics center layout optimization. Shijiazhuang is now known throughout the region densely populated by the investigation ten, when the outbreak of unexpected events will be the focus of the food needs of the region, which is in Shijiazhuang plain areas because the location and convenient transportation is a major capital city population dense, with build conditions for food emergency logistics center, the rest of the region also has several good conditions to build grain emergency logistics center (Kotler. Philip.1991).

Location and spatial distribution of various food emergency logistics supply between the points as shown in Table 1 and shown in Figure 1. Knowning food emergency logistics node coverage area of $50 \mathrm{~km}$, in order to reduce the human and financial burden in the region, to improve the food supply capacity. Need to build as little food emergency logistics center, to calculate the best food emergency logistics center layout scheme (Lan, Hongjie. Tian, Yongbin.Wei, Jinshi.2013).

According to Figure 1 can determine the emergency food needs of a set of nodes are $\mathrm{I}=$ $\{1,2,3,4,5,6,7,8,9,10\}$,food emergency logistics center candidate point set are $J=\{1,2,3,4,5,6,7,8,9,10\}$, then one by one calculation under constraints judge set AJ emergency logistics center facility node AJ covered emergency food supply points and it can be able to support relief food supply points emergency logistics center set BI. For example when the emergency food needs of the region as a region 1 food emergency logistics center within 50km range it can cover for $A J=\{1,2,3,4\}$. At the same time when alternative food emergency logistics facility node 1 emergency food supply points as possible to cover the area of a set of $\mathrm{BI}=\{1,2,3\}$, the same way we can obtain various other points in the set as shown in Table 2 :

Table 2 Model node position set

\begin{tabular}{|c|c|c|}
\hline Area designations & AJ & BI \\
\hline 1 & $1,2,3,4$ & $1,2,3$ \\
\hline 2 & $1,2,4$ & $1,2,4$ \\
\hline 3 & $1,2,3$ & $1,2,3$ \\
\hline 4 & $1,2,4,6$ & $1,2,4,6$ \\
\hline 5 & 5,7 & 5,7 \\
\hline 6 & $2,3,4,6,7$ & $2,3,4,5,6,7,8$ \\
\hline 7 & $5,6,7,10$ & $5,6,7,10$ \\
\hline 8 & 8,9 & 8,9 \\
\hline 9 & $8,9,10$ & $8,9,10$ \\
\hline 10 & $7,9,10$ & $7,9,10$ \\
\hline
\end{tabular}

As can be seen by comparing the A $(6)=\{2,3,4$, $6,7\},[A(6)]=5$ compared to other logistics centers and coverage area is the largest, so choose $\mathrm{j}=6$, in A (6) in accordance with the size of the sort $\mathrm{Bi}$, according to the good order of the row assigned 5,8,2,3,4,7,6. 7 nodes to 6 nodes the logistics facilities as part of its emergency services objects. Followed by further determine emergency food needs point I 
$=\{1\}$,emergency food logistics center candidate point set $\{1,9,10\} \mathrm{J}=\{2,3,4,5,7,8\}$ As shown in Table 3:

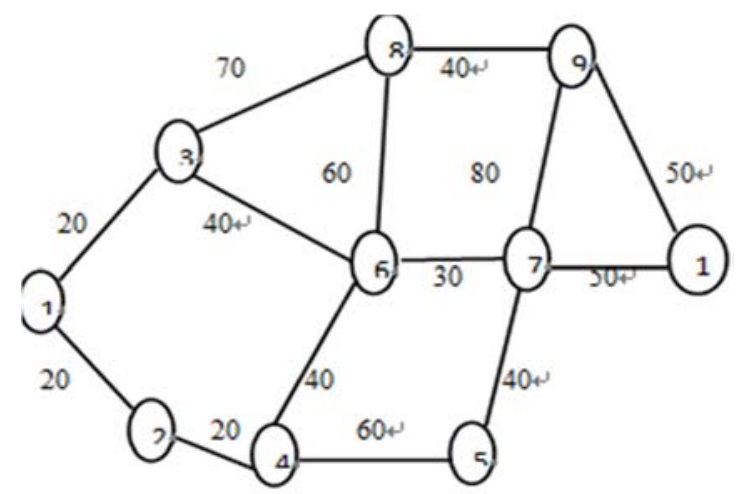

Fig. 1 distance map of each food demand between notes

Table 3 Model node position set

\begin{tabular}{|c|c|c|}
\hline Area designations & AJ & BI \\
\hline 1 & 1 & 1 \\
\hline 2 & 1 & 1 \\
\hline 3 & 1 & 1 \\
\hline 4 & 1 & 1 \\
\hline 5 & & \\
\hline 6 & & \\
\hline 7 & 10 & 10 \\
\hline 8 & 9 & 9 \\
\hline 9 & 9,10 & 9,10 \\
\hline 10 & 9,10 & 9,10 \\
\hline
\end{tabular}

It can be drawn by comparing the observed A (9) $=\{9,10\},[\mathrm{A}(9)]=2$ in the remaining points are after the biggest and the position on the list, so choose $\mathrm{j}=$ 9. 9 and 10 two regions as assigned logistics center service object 9. At this point the emergency food needs of $I=\{1\}$, the food emergency logistics facility candidate point set $\mathrm{J}=\{1,2,3,4,5,7,8,10\}$, according to the above iteration algorithm once again to give $\mathrm{j}=$ 1 , it is necessary to set up a regional food emergency 1 logistics center to meet the emergency food needs of the region 1,2,3,4 people.

To sum up the above calculation can be seen in this example, the optimal quantity of food emergency logistics center be in Hebei Province, the optimal layout area should be selected among in 1, 6, 9, it is provided at the logistics center bridge West (1), gao cheng (6), Jinju downtown (9). Not only these three cover the entire emergency food needs of the region, covering all of the victims in settlements, grain storage, food distribution stations can guarantee logistics nodes the total number of the smallest, effectively saving construction costs, so it is the most appropriate in this three-building food emergency logistics center .

\section{CONCLUSION}

This paper first introduces the concept and characteristics of emergency logistics, and then introduces the meanings and characteristics of emergency logistics grain, as well as the grain logistics current situation and existing problems, and the core is the layout of the emergency logistics center and optimization. This article first through the location set covering model from ten of the most important agricultural regions of the three best as a logistics center location selection, in order to test to establish the scientific rationality of logistics center. Through this method to establish a network that covers the whole logistics center layout, make emergency logistics level has reached a higher level.

\section{REFERENCES}

B.Ombuki.2006. Multi-Objective Genetic Algorithms for Vehicle Routing Problem with Time Windows, Applied Intelligence.

Denis R. Towill. 1997. FORRIDGE - Principles of good practice in material flow [J]. Production, Planning \& Control.

Kotler. Philip.1991.Marketing Management: Analysis, Planning, Implementation and Control [M]. NJ: Prentice, Hall, Englewoodeliffs.

Lan, Hongjie. Tian, Yongbin.Wei, Jinshi.2013.Forecast of Food Refrigerated Warehouse in Beijing .LISS 2012 _ Proceedings of 2nd International Conference onLogistics, Informatics and Service Science, 1047 - 1052.

Theodore P. Stank, Patricia J. Daugherty. 1997. The impact of operating environment on the formation of cooperative logistics relationship [J]. Transportation Research Part E. 